\title{
BOSTON - 1982 MEETING
}

\section{More went, and more went on}

As will be no surprise to the readers of this Bulletin, the MRS held its annual meeting in Boston during November. The meeting, most commonly referred to among materials scientists as "the Boston meeting" or simply "Boston", continued the trends set in years past. Attendance this year was in excess of 1200 , with a large non-U.S. representation. The meeting comprised, as is now traditional, a collection of individual symposia. This year, fifteen symposia covering topics from atomic defects to phase diagrams and interface physics to laser diagnostics were presented. Each contained presentations at the forefront of materials research in its respective field of study, and was characterized by a strongly interdisciplinary approach to the topic.

While the Boston meeting carried forward the focused, topical approach and spirit of the MRS, it bettered past meetings in several quantitative measures. More symposia chose to publish proceedings volumes this year than ever before. All told, nine symposia produced the raw material for the Society's Symposium Proceedings Series or other special publications. These proceedings are increasingly regarded not only as excellent reference sources but also as excellent vehicles for the exposure of new, exciting materials research results. Participation of corporate sponsors in the various symposia also hit a new high this year. In total, 39 corporate sponsors assisted in the production of the meeting. Finally, more comments to the effect that the meeting was "too good," "too frenetic," "too exhausting," or "too crowded" were recorded at the registration desk than ever before. While comments of this sort are typically taken as indications of a job well done by the organizers, the message did get transmitted to the council for consideration at it's gathering in Boston.

The Von Hippel award was also presented at the meeting, although not as originally scheduled. The MRS learned the harsh realities of politics, hotel management and schedule alteration logistics when it was discovered that the award ceremony was scheduled for election eve in the designated campaign hotel of the eventual election winner, Governor Mike Dukakis. When the MRS, the hotel management and the governor faced the issue of ballroom occupancy for that particular evening, there was little recourse but for the relatively smaller group to yield to the larger. The Von Hippel ceremony was consequently rescheduled for the following evening, when Professor Clarence M. Zener of Carnegie-Mellon University was presented with the award. His receipt of the Von Hippel prize occasioned an outpouring of congratulatory messages from, among others, President Ronald Reagan, Governor Dukakis, and previous recipients.

The Boston meeting this year also witnessed the occurrence of the first MRS sponsored short course. This course, taught by R. Dawson of Sandia National Laboratory, covered the important technological area of liquid phase epitaxial growth. Its participants reported that the level of presentation, the subject matter and the lecture materials were of significant value.

\author{
j111. IIIIF 1100 SE \\ Wistivitox \\ October 26, 1982
} It is my pleasure to extend greetings to the members
of the Materials Research Society on the occasion of
its annul meeting.
The study of materials constitutes one of the most
exciting and important areas of research today. Much
of today's advanced technology is made possible by
developments in materials science of recent years, and
tomorrow's technologv will depend even more heavily
on the progress you and your colleagues make in the
future. From airplanes to microcircuits, materials
soience will play a critical role in keeping American
high-technology industries strongly competitive.
In conveying my best wishes for the Society's con-
tinued success in stimulating research, I also
congratulate Professor Clarence Zener as the l982
recipient of the Society's von Hippel Award for his
contributions to the field. 